\title{
Theme-based Group Teaching of College Oral English: Endorsed by Students in Chinese EFL Context
}

\author{
Fen Gao \\ School of Foreign Languages, Shaanxi Normal University, Xi'an 710061, China \\ E-mail: gaojjyy@126.com
}

\begin{abstract}
In this study the author tries to assess the effects of Theme-based Oral Approach (TOA) on the oral English proficiency of non-English majors as well as students' leaning motives and interests resulted from the approach in EFL class of China. The study follows the quantitative and qualitative method in light of questionnaire, interview, class observation with the causal-comparative study between treatment group and control group. The result shows that a majority of students with TOA improved their oral English learning more than those with Traditional Teaching Method (TTM). It also finds that TOA is able to motivate the students to speak in class and a certain percentage of students can overcome their psychological problems in expressing ideas. The findings are that TOA affects students' achievement in a favorable way which provides some theoretical, methodological and practical implications.
\end{abstract}

Keywords: Theme-based Oral Approach (TOA), Traditional Teaching Method (TTM), Group work, Dynamic classroom activities, Student-centered, Oral English proficiency

\section{Introduction}

Oral English is often underdeveloped for English non-majors in their university study in China. A large number of students are found to be spoon-fed and hardly utter any words upon graduation. A combination of potent inhibitors is responsible for this situation: large class size, inappropriate teaching method and time constraints. On the basis of analyzing the requirements for college English teaching, the paper intends to argue the importance of taking these factors into consideration and tries to resolve it in terms of Theme-based Oral Approach (TOA).

The learners' oral English proficiency is a subject that drew attention to itself as early as the 19th century. Then some researchers found that learners' motivation and learning strategies have a direct influence on learners' acquisition of speech (Ellis, 2000; Brown, 2002). When time went on, a succession of new perspective as to oral English proficiency through readers' theatre (Leong, 2002), group work (Bassano, 2003), and drama (Miccoli, 2003) have been presented. These studies indicate that language researchers have come to attach greater importance to oral English by means of various measures in language teaching than before.

By contrast, English teaching and learning research in China just follows the western trend and remains a certain distance from it. A lot of researchers such as Xu (1998), Hu (2001), Wen (2002), He (2002) and Jiang (2006) have contributed greatly. Consequently, the teaching model of theme-based approach sprang up in the field of EFL teaching, which refers to teaching English in theme-based context in the student-centered classroom under integrated curriculum, aiming at promoting learners' English proficiency. This issue has been early put forward and discussed by Huang and Gu (1996); Zhe Jiang University has carried out theme-based approach in the college of foreign languages, by means of contrastive analysis between a controlled class and an experimental class (Ying, 1998; Shan, 2000; Shang 2008). The experiment, as a result, confirms that theme-based approach is able to motivate students in language learning.

What's more, China's college English teaching has existed for almost twenty years in which it has witnessed several stages of development and now it comes to the stage of maturity and perfection. Its requirement on oral English has also changed from zero-starting point to what today's College English syllabus (for Undergraduates of Institutions of Higher Learning) [Revised, 1999] which states: the chief goal of college English instruction is to help students develop a relatively high level of competence in listening, speaking, reading, writing, and translation, enabling them to communicate in English. Furthermore, according to the latest official file on Teaching Requirements for College English Curriculum (2004) from SECC, spoken English is put in the foremost place. It says: the teaching objective of college English is to develop students' ability to use English in an all-round way, especially in listening and speaking, so that in their future work and social interactions they will be able to exchange information effectively through both spoken and written channels. In this file, the Higher Requirements are students should be able to understand longer dialogues and passages, and grasp the key points even when sentence structures are complicated and views are only implied. They should, by and large, be able to understand radio and TV programs produced in English-speaking countries, comprehend lectures related to their areas of specialty and grasp the gist. 


\section{Significance of the study}

Three fundamental factors are involved in TOA: two-way dynamic complementary learning environment, teaching content associated with the theme and learners' autonomous awareness. Three factors are interrelated and interacted with each other. It can be seen that the classroom teaching is divided into three parts, input, practice and output. In the stage of input, students are possible to get access to the language materials as well as its theme and value. And the practice stage is the core, in which students process the input by reconstruction and internalizing. This stage must be accomplished with the assist of the teachers to organize the optimal classroom activities. Therefore, most importantly, the whole process is humanized and dynamic, which consists of a succession of classroom activities such as group discussion, role play, debate, and questions \& answers (See Figure 1).

In spite of the above-mentioned requirements in English teaching, one should not ignore there is still a great gap between what we have been doing today and what is required and expected in 21st century. Some graduates still behave like deaf-mutes and their proficiency cannot meet our anticipation. In a word, the world, society, and the government all demand for fluent spoken English of college students, which justifies itself to introduce a brand-new approach — Theme-based Oral Approach (TOA).

So far few studies conducted have been done with college undergraduates of non-English majors in view of oral English specifically. Thus, this thesis expounds TOA from the theoretical perspective of cognitive psychology and constructivism by integrating the meaningful classroom teaching of teachers with autonomous learning from the students in terms of group activities. In order to promote oral English output of undergraduate English non-majors, TOA is carried out on the basis of teaching materials entitled New Horizon College English. Therefore, the purpose of this study is to assess the effects of Theme-based Oral Approach (TOA) on the oral English proficiency of non-English majors as well as students' learning motives and interests resulted from the approach in EFL class of China. The research questions to be addressed in this thesis are as follows: Do students evaluate positively about the Theme-based Oral approach in terms of group work? What can be found from that? Is theme-based oral approach valuable and helpful to improve oral English for English non-majors in EFL class compared with traditional teaching method? Why and how?

\section{Theoretical Framework}

Students, guided by TOA, are task-based to communicate with teachers or to each other, thus digesting what they learned from the text and output $\mathrm{i}+1$. Theme-based approach just finds its way into the theory proposed by Krashen (1982), namely acquisition is acquired through $i+1$ called comprehensible input, in which i refers a certain amount of input which is the acquirers' level of language competence in large quantities, while 1 is an indefinite index, representing the input supposed to be the slightly higher level than students' faculty. Krashen states the best way to teach oral English is to offer sufficient input in large quantities and too easy or too difficult is not suitable. The key issue is how to assist the students to transform the input to which they are exposed to internalized intake. In short, acquisition of the target language is on the whole a learning process to change mainly input into intake through a certain approach-TOA. The input hypothesis predicts that language classroom is an excellent place to second language learning by taking a series of dynamic classroom activities, because within an hour learners can provide comprehensible input of a whole day in class. It is also true of TOA that during the process of regular classroom, the teacher with the help of all kinds of possible teaching media, imparts knowledge and trains students' skills to accomplish the task gradually. And the learning of fluent oral English is acquired naturally in the continuous comprehensible input in the relaxing classroom. TOA can not agree more to the input hypotheses in its realization.

The author attempts to illustrate TOA from the perspective of psychology, specifically in view of constructivism. In TOA teaching, students are the center of the class, while the teacher acts as facilitator, assessor, organizer, and participant. The related topics and questions are discussed as the teaching content with the students' autonomous and cooperative learning. The students then self construct their own knowledge system with the help of the teacher. In this connection the learning theories of Piaget (1980) should be mentioned, as he gave a clear description of learning as a process of construction rather than a transmission from one to another in a pure form. Obviously, constructivist learning theory is based on the knowledge by connecting new knowledge to previously learned knowledge. Constructivism may be viewed as a theory of cognition, of learning, of teaching, even a theory of education. Constructivists believe that individuals actively construct their own internal sets of meaning or understandings and that knowledge is not a mere copy of the external world, nor is it acquired by passive absorption or by simple transference from one (a teacher) to another (a learner).

The concept of constructivism claims that knowledge is rather made, not acquired. Knowledge is constructed through interaction with many knowledgeable others in community. And language learning means altering learned construction of knowledge through assimilation and accommodation. A person tries to associate or assimilate 
unfamiliar discourse with originally cognitive structures retained in his mind, adapting himself to the unknown material, changing accordingly his cognitive structure in the context and situation around him. In recent years, constructivism focuses on the significance of students' own knowledge system, but weakens the roles of teacher in the teaching process. Teaching cannot control but can only provide "material" in a broad sense. The learner then decides autonomously how and with what consequences he takes up and uses this "material" in his construction process. Presumably, constructivist learning suggests that instruction must start with the knowledge, attitudes, and interests of the students so they can create their personal constructions of meaning. TOA best illustrates the theory of constructivism.

What's more, cooperative learning can be well found in TOA. The group activities on TOA desire for cooperative learning (CL) among students. Cooperative learning refers to the instructional use of small groups, in which students work together to maximize their own and each other's learning. In CL classroom, class members are organized into small groups after receiving instruction from the teacher on the basis of theme. They then work through the assignment until all group members successfully understand and complete it. Cooperative efforts result in participants striving for mutual benefit so that all group members can gain from each other's efforts. Therefore, TOA follows to organize the class in groups and group members can comment each other in a positive and constructive manner through the use of appropriate social skills. It is worth mentioning that all the members must perceive that they have to swim or sink together when they are in the same group. And such an understanding can be induced by having all the group members set up the goal at the beginning together, design the work plan and bear the work load together and eventually receive reward for the final achievement together. Every member of the group is responsible to each other and everyone is due to make a fair contribution to the achievement of the group goal. Simultaneously, group members help, encourage, support and learn from each other when working towards the group goal.

\section{Methodology}

\subsection{Participants}

The participants are 286 second-year English non-majors from three different Universities (Shannxi Normal University, Chang An University and Northwest University) in China. All the participants, who enrolled in college in the year of 2008, had studied English for six years in junior and high school and one semester in college ranging from 17 to 20 years old. And most of them have never accepted oral English training and their oral English proficiency remains low. Table 1 shows the students' participation of various departments from different universities. All classes are taught by the experienced teachers with a certain teaching method for the purpose of spoken English. What's more, the English textbook, New Horizon College English, compiled by Shutang Zheng is shared and employed under the guidance of the specific teaching method.

\subsection{Instrument}

In this study, the independent variable is the teaching method; the dependent variable is the improvement of students' oral English proficiency as well the students' feedback towards the teaching method. Three natural classes (136) are randomly chosen from 3 different universities as treatment groups taught with TOA by the experienced teachers, while the rest three (150) follow the Traditional Teaching Method (TTM) as control groups taught by the same experienced teachers (Table 2). This classroom teaching and learning last the whole semester in order to see the students' improvement and attitude toward their own teaching method.

The study follows the quantitative method in light of questionnaire on the two comparative groups, The subjects of treatment groups and control groups have been orally tested at the beginning of the semester (Feb, 2009) and retested at the end of the semester (Jun, 2009) in order to see whether the students' oral English proficiency have improved or not under the different teaching methods and whether their improvement is statistically meaningful over time. Both tests were undertaken by 3 experienced English teachers, one of which is an American in terms of face-to-face communication. The tests consist of a picture description and 3 questions raised by 3 respective teachers and the students are asked to express their ideas within stipulated time (5mins). The author enacts the detailed test rubrics for scoring in terms of clarity, fluency, accuracy, grammar, as well as pronunciation and intonation (100 points numeric scoring) so that the testers have the explicit and objective rules to follow. I also employ the statistical software (16.0) to make a synthesis and analysis between the pre-test and the post-test. Fuzzy comprehensive evaluation is employed in statistics calculation and analysis, too.

What' more, the questionnaire called Reflection upon Theme-based Oral Approach is used in which there are thirty five items illustrated both in English and Chinese to make sure a full understanding after the students have experienced the TOA for one term. 136 participants from the treatment group are required to evaluate their reflections upon the approach in light of seven aspects, i.e. theme, teacher, students, teaching materials, teaching \& learning environment, classroom activities and teaching effects. In each aspect five statements are involved, judging 
from the knowledge of the students. The questionnaire is designed using a Likert Scale format, in which the students respond on a four-point scale: 1-Strongly Agree, 2-Agree, 3-Disagree, and 4-Strongly Disagree. In order to avoid ambiguity in interpretation caused by the possibility that the respondents rate the scale uncertain or neutral for all the statements in the questionnaire, 4 scales are adopted without neutral scale. Simultaneously, all the respondents are entitled to provide their comments freely about each statement. Their comments would be of interest for two reasons. Firstly, it is to see if they are consistent with what they say with reference to the statements. Secondly, it is to examine if they have strong feelings about any teaching aspect related to their teaching method, which all result in more vivid reference for the study.

\section{Data Collection}

The whole data collection lasts for one semester about five months and was conducted from February to June 2009. Both pre-test and post-test are implemented in a quiet classroom on weekends by 2 Chinese English teachers and one foreign teacher for about 5 minutes per person. Students are told to come into the classroom one after another according to their student number. And students are instructed not to do any preparations ahead of time and the fact is there is not any review questions for them to get prepared. Meanwhile, all of the students are informed to relax and encouraged to treat the test as a communication rather than a exam. However, the students would be asked to stop talking when 5-minutes are up so that students should be careful about the time limit. Eventually, the final score of the students' score is the average of the 3 teachers in terms of 100-points numerical scoring.

In order to exclude all the confounds and control all of the variables that may have the impacts on the teaching effects, the author uses the T-test to prove that the treatment group and control group do not have any significant difference in terms of oral English level at the beginning of the semester. All the final scores of pretests are turned to be valid to perform the statistical analysis. Thus they are recorded and input into the SPSS 16.0 and the average is 64.93 (treatment group) and 65.23 (control group) (Table 3). The significant level is $0.724(>0.05)$ which shows that treatment group and control group are no significantly different in the initial stage (Table 4). After the teaching and learning practice for the whole semester, all of the participants in two groups are tested again. All of the scores are rerecorded and calculated.

The questionnaire is also completed by the end of June in the academic year of 2008-2009. The teacher explains to the classes the research function of the questionnaire. Then the questionnaire is presented as a normal classroom activity for the students to respond for each statement within 15 minutes. The author observes the answering process in order to make sure that the participants do it seriously and they are told that their honest responses and sincere supports would be greatly appreciated. The survey is expected to be finished in class and questionnaire forms are later collected to analyze. Students are allowed to write down the comments on some specific statements. It turns out that all the participants hand in the questionnaire papers, thus the data collection rate is $100 \%$.

\section{Results and discussion}

\subsection{Results from the test scores}

All of the pre-test and post-test scores from the treatment group and control group are input into the SPSS. Table 3 shows that the mean, standard deviation together with the standard error mean from different groups under different teaching method. The scores for both tests are found to be normally distributed with bell-shaped curve. It can be seen from the table 3 that mean of the pre-test for treatment group (136) and control group (150) are respectively 64.93 and 65.23, which implies that the two groups are in similar oral English proficiency. T-test also indicated the two groups are actually no significant different to each other. In addition, the means of the post-test for both groups are 72.04 and 65.69, which manifest there is some amount of progress compared with the pretest (64.93 and 65.23) for both groups. Table 3 also indicates that standard deviation of treatment group $(\mathrm{sd}=6.629)$ and the standard deviation of control group ( $\mathrm{sd}=7.311)$ in pre-test are much higher than post-tests, which implies that the students scores in pre-test are more spread out over a large range of values. In other words, the post-test scores are more clustered around the mean with the relatively smaller degree of dispersion. It is found that there are a few scores like 27,34 or 88,91 in pre-test which are toward one extreme or other. However, in post-test the scores are more pretty bunched together to the mean.

What's more, the author performs the T-test in order to test whether the students' progress under TOA and TTM are not likely to occur by chance, i.e. the results are statistically significant (See Table 4). The results of Levene's test for equality of variance in terms of pre-test are 2.211 (F value) and 0.138 (Sig. value), which means there is no significant difference, i.e. equal variances. Under this circumstance, we find the first line of t-test for equality of means are respectively -0.354 ( $\mathrm{T}$ value), 284.000 (df), 0.724(2-tailed sig), -0.293 (mean difference), which show that the result (sig $=0.724)$ is not significantly different. That is to say, the result between the treatment group and control group in the pre-test stage does not have any statistically significant difference. Then the paired T-test is used to see 
the amount of progress from pre-test to post-test for both treatment groups and control groups respectively. Table 5 indicates in pair 1 there is no significant difference $(\mathrm{t}=-1.446, \mathrm{df}=149,2$-tailed $\mathrm{sig}=0.150, \mathrm{p}>0.005)$ about the progress achieved from the pre-test to post-test under the guidance of TTM. Even it can be seen from table 3 the mean score of control group increases from 65.23 to 65.69 , but there is no statistically significant meaning. In contrast, there is the significant improvement from the pre-test to post-test in that $\operatorname{sig}=0.000(\mathrm{p}<.005), \mathrm{t}=-17.694$, $\mathrm{df}=135$ under the TOA. In combination with the mean difference from 64.93 to 72.04 on treatment group compared with 65.23 to 68.69 on control group, the participants under TOA improved more than control group with TTM. To put it brief, the progress under the guidance of theme-based oral approach has the more statistically significant meaning than the one under traditional teaching method.

\subsection{Results of the questionnaire}

The trends of participants' perception have formulated on their responses to the questionnaire items. Table 6 is a summary of the questionnaire on the basis of TOA:

To make the graph easier and clearer, 4 degrees of evaluation are reduced to 2 levels: namely "Agree" and "Disagree" by putting "Strongly Agree" and "Agree" together and "Strongly Disagree" and "Disagree" together. Figure 2 shows more clearly that a high percentage of students have a positive (Strongly Agree or Agree) attitude towards TOA. And it can be seen that the distribution of the degree of agreement on each factor is fairly even, which does not span the large distance and the figures of subjects who are for the factors are all above the frequency line of 100. Based on the calculation, the average percentage of affirmative attitudes towards each factor has reached to $89.7 \%, 80.9 \%, 76.5 \%, 80.1 \%, 76.5 \%$, and $85.3 \%$ respectively.

From the above analysis, it can be easily seen that a high rate of subjects applaud TOA. What's more, the author adopts 136 samples to have the fuzzy comprehensive evaluation done as a whole, aiming at proving the popular acceptance about TOA among the participants (See table 7). The fuzzy statistics is applied to analyze the degree of acceptance for 7 aspects of theme-based oral approach, namely theme, teacher, students, teaching materials, teaching $\&$ learning environment, classroom activities and teaching effects.

Accordingly, the results are as follows: if it is supposed that 40 represents "Strongly Agree", 30 refers to "Agree", 20 stands for "Disagree", and 10 indicates "Strongly Disagree" in evaluation, the result vector on the teaching effects $(\mathrm{F} 7=32.3434)$ in table 7 is between 30 and 40, which indicates TOA is confirmed to be satisfactory and efficient among the students. This result proves the approach has got the upper hand upon others and prospects wider use in the near future. In addition, the corresponding sequence of 7 factors according to the result vector is as follows: theme $>$ classroom activities $>$ teacher $>$ students $>$ teaching materials $>$ teaching $\&$ learning environment. The sequence clearly represents the degree of evaluation that the students hold towards TOA: theme (35.8111) is put in the first important factor which is considered as the most concern; classroom activities (34.1035) follows next, which demonstrates that the students are very much fond of them; teacher(33.0488) and students (33.0212) are listed the third, and the last is teaching materials(28.5890) and teaching \& learning environment (27.8465), which are weakest points and need to be further strengthened in the following teaching.

\section{Results and findings}

All in all, the findings are obvious and valuable based on the comparative study upon two groups. It is generally concluded that the students under the guidance of Theme-based Oral Approach (TOA) are more likely to improve their oral English abilities and more enthusiastic and interested in oral English learning compared with the traditional teaching. To sum up, 3 findings can be summarized as follows:

\subsection{Positive interdependence}

The students in theme-based classroom accomplish a diversity of communicative tasks in cooperative groups in which they share a common goal working productively. Each student plays the essential role and has a definite sense of group or team, in that the success or failure of a cooperative group is dependent on the efforts of all of its individual members. Members of the group listen to each other, trust each other and take turns and interaction is promoted. Students talk and discuss for the most time at class, while the teacher acts as a listener, organizer and consultant.

\subsection{Individual accountability}

Teachers under theme-based oral approach shoulder more responsibility to form the heterogonous groups to maximize each student's contributions to the group and to provide each student with opportunities to learn from others. Students have a positive self-image reinforced by the group. For example, an extroverted or confident student may be assigned the role of Reporter in the activity, while the one fond of writing may be named the Recorder. Members feel secure and accepted, and they are more actively and autonomously engaged in and out of class. 


\subsection{Development of social skills}

It is also observed that individual members in TOA classroom have developed their social skills after a semester of learning process, such as teamwork, communication, and problem-solving in group interacting. The students learned how to work together as a team in the relaxing and competitive atmosphere. In addition, they get access to some group interaction skills in turn-taking, listening, encouraging, helping, and accepting others' opinions and disagreement. In contrast, the control group is weaker in communicating with each other and always restrict themselves in their limited level of oral English as well as excessive anxiety in speaking in public.

\section{Limitation and suggestions}

To sum up, TOA has shown to encourage and support most affective factors which correlate positively with oral English learning. However, it does encounter some resistance while conducted in college classroom. Firstly, grouping students may cause a period of mess and disorder in classrooms. Traditional Chinese culture and individual difference, to some extent affect the efficacy of cooperative and communicative learning; thereby students' motivation can not be well stimulated. What's more, over-reliance on first language in the stage of discussion is a problem in practicing TOA. And the study finds that lacking group reward either verbally or materially reduces students' sense of responsibility and group honor. At last, the application of TOA in reality is a time-consuming process and makes a great difference to the normal traditional teaching. It is found that some students are still concerned about the grammatical points from the questionnaire the author has done.

In short, some factors need to be taken into consideration when implementing TOA. And I would provide the corresponding solutions for future research.

First of all, if the teacher makes students understand the interacting task, build correct attitude, master effective learning strategies, and respect their differences, TOA can be organized well and turns perfect, thus producing the maximum potentials to be of benefits. Furthermore, it is suggested that the students are encouraged to be more risk-taking and venture to express themselves logically and fluently without caring much about grammatical errors by using all the possible chances. The teacher needs to keep on emphasizing upon the participating awareness of the students in the relaxing atmosphere, and over-correction of oral mistakes is still not preferred. Secondly, more classroom activities should correspond with the approach and deserve to be explored and applied in the near future. And if it is possible, the author recommends that the separated oral English class (two periods one week) be held and oral English should occupy a certain part (20-30percent) of the final exam. And what's more, the oral English exam should be gradually objective and systematic. Thirdly, it can not be omitted that TOA succeeds in aiding students how to communicate with others cooperatively in fluent spoken English, but not emphasized on autonomous study of the students. The students should assimilate the more consciously to learn through practice on their own and be more encouraged to read related books under the guidance of the teacher. While teachers are supposed to show confidence in them, place high hope rather than find faults with them. Finally, as to the teaching materials, it is recommended that the textbook could be a better one if it takes more factors into account, such as the authenticity of language materials and communicative tasks. All the selected materials should not be adapted t but kept in nature. Section A in each unit is wiser to be altered as a dialogue or conversation associated with the shared theme, providing an authentic example to communicate. Besides, a certain number of exercises in the textbook should be compiled for the sake of communication since oral English can only be promoted in the continuous communicative practice.

To conclude, this study about TOA is applied successfully among 136 students in 3 universities. Therefore, it proves that the aforesaid findings are universally applicable to some extent. However, owing to the limitation, there is much space left for the further research. The followings are the suggested topics: how should curriculum materials be designed and improved more appropriately for theme-based oral approach? How should the classroom teaching and learning and autonomous study be well combined so as to improve the oral English proficiency? Is it necessary to hold the oral test for the English non-majors to be a part of their final exam? If yes, how should it be more objective and systematic in practice? It is hoped that the insights provided by this paper will be useful for college English teachers if they determine to develop their students' oral English proficiency. It confirms that a good understanding of TOA can assist teachers to develop a range of tactics which will enable their language classes to become more dynamic and meaningful.

\section{References}

Bassano, S. (2003). Helping ESL students remember to speak English during group work. TESOL Journal. 12(1), $35-36$.

Brown, H. D. (2002). Principle of Language Learning and Teaching. Beijing: Foreign Language Teaching and Research Press. 
Davies, P. and Pearse, E. (2002). Success in Language Teaching. Shanghai: Shanghai Foreign Language Education Press.

Duan, L. M. (2004). Exploring the modes of foreign language classroom teaching. Chinese Higher Education Research. (4), 90-91.

Ellis, R. (2000). Understanding Second Language Acquisition. Shanghai: Shanghai Foreign Language Education Press.

Gu, X. L., Huang, F. R. \& Wang, S. (2004). Cooperative learning and drama performance: oral teaching discussion of college English. Overseas Foreign Language Teaching, (2), 55-61.

Harmer, J. (2004). How to Teach English. Beijing: Foreign Language Teaching and Research Press.

He, G. K.(2002). English Teaching Research. Guangzhou: Guangdong Higher Education Press.

Hu, C. D. \& Wang, C. R. (2001). On English Teaching. Nanjing: Guangxi Education Press.

Huang, Y. Y. \& Gu, Y. G. (1996). Students-centered integrated teaching method of college English. Foreign Language Teaching and Research, 106(2), 9-13.

Jiang, J. Y. (2006). Study of communicative activities in foreign language classroom. Hangzhou: Zhejiang University Press.

Krashen, S. D. (1982). Principles and Practice in Second Language Acquisition. Oxford: Pergamon Press.

Leong, P. N. C. (2002). Teaching oral English through Readers' Theatre. TESOL Journal, 11(4), 34-35.

Lin, L. (2004). Experience English: distinction of new concepts between teaching and learning. China University Teaching, (2), 46-48.

Miccoli, L. (2003). English through drama for oral skills development. ELT Journal, 57(2), 122-129.

Palmer, H. E. (2009). The Oral Method of Teaching Languages. BiblioBazaar, LLC.

Piaget, J. (1980). The psychogenesis of knowledge and its epistemological significance. In M. Piattelli-Palmarini (ed.). Language and Learning. London: Routledge and Kegan Paul.

Shan, L. (2000). Struggling to reform the teaching mode of college English. China Higher Education. (13/14), 40-41.

Shang, J. L. (2008). Exploring interactive oral teaching mode. Zhengzhou Railway Vocational and Techinical College. 20(12), 71-74.

The Ministry of Education. (1999). College English syllabus (for Undergraduates of Institutions of Higher Learning). Shanghai: Higher Education Press \& Shanghai Foreign Language Education Press.

The Ministry of Education. (2004). Daxue yingyu kecheng jiaoxue yaoqiu [Teaching Requirements for College English Curriculum]. Retrieved June 17, 2004, from: http://www.edu.cn/20040120/3097997.shtml.

Wen, Q. F. (2002). Oral English Testing and Teaching. Shanghai: Shanghai Foreign Language Education Press.

Xu,G. Z. (1998). English Teaching of China. Beijing: Foreign Language Teaching and Research Press.

Yang, Y. Q. (2004). Experiencing the new teaching requirements for college English. China University Teaching. (6), $42-43$.

Ying, H. L., He, L. Z. \& Zhou, S. B. (1998). College public English Teaching Reform: students-centered theme approach. Foreign Language Teaching and Research. 116(4), 22-26.

Zhang, P. X. (2005). Practice and research of oral teaching of college English. University Education Science. 89(1), 53-55.

Zeng, F. G. (2004). College Teaching and Research. Changsha: Hunan University Press. 
Table 1. Students' Participation in the Study

\begin{tabular}{|c|c|c|}
\hline University & Class Description & Number of participants \\
\hline \multirow{2}{*}{ Shaanxi Normal University } & Marketing & 43 \\
\cline { 2 - 3 } & Physical Education & 54 \\
\hline \multirow{2}{*}{ Chang An University } & Mechanics Engineering & 53 \\
\cline { 2 - 3 } & Statistics & 47 \\
\hline \multirow{2}{*}{ Northwest University } & Software Engineering & 40 \\
\cline { 2 - 3 } & Geology & 49 \\
\hline
\end{tabular}

Table 2. Students' Participation in TOA and TTM

\begin{tabular}{|c|c|c|}
\hline University & TOA (136) & TTM (150) \\
\hline Shaanxi Normal University & Marketing(43) & Physical Education(54) \\
\hline Chang An University & Mechanics Engineering(53) & Statistics(47) \\
\hline Northwest University & Software Engineering(40) & Geology(49) \\
\hline
\end{tabular}

Table 3. Group Statistics in Mean, Standard Deviation and Standard Error

\begin{tabular}{|c|c|c|c|c|c|}
\hline & group & Number & Mean & Std. Deviation & Std. Error Mean \\
\hline \multirow{3}{*}{ Pre-test } & TOA & 136 & 64.93 & 6.629 & 0.568 \\
\cline { 2 - 6 } & TTM & 150 & 65.23 & 7.311 & 0.597 \\
\hline \multirow{2}{*}{ Post-test } & TOA & 136 & 72.04 & 5.998 & 0.514 \\
\cline { 2 - 6 } & TTM & 150 & 65.69 & 5.830 & 0.476 \\
\hline
\end{tabular}

Table 4. Independent Samples T-Test of Pre-test

\begin{tabular}{|c|c|c|c|c|c|c|c|c|}
\hline \multicolumn{2}{|c}{} & \multicolumn{2}{c|}{$\begin{array}{c}\text { Levene's Test for } \\
\text { Equality of Variances }\end{array}$} & \multicolumn{6}{c|}{ t-test for Equality of Means } \\
\cline { 2 - 9 } & F & Sig. & t & df & $\begin{array}{c}\text { Sig. } \\
\text { (2-tailed) }\end{array}$ & $\begin{array}{c}\text { Mean } \\
\text { Difference }\end{array}$ & $\begin{array}{c}\text { Std. Error } \\
\text { Difference }\end{array}$ \\
\hline \multirow{2}{*}{ pretest } & $\begin{array}{c}\text { Equal } \\
\text { variances } \\
\text { assumed }\end{array}$ & 2.211 & 0.138 & -0.354 & 284.000 & 0.724 & -0.293 & 0.828 \\
\cline { 2 - 9 } & $\begin{array}{c}\text { Equal variances } \\
\text { not assumed }\end{array}$ & & & -0.355 & 284.000 & 0.723 & -0.293 & 0.824 \\
\hline
\end{tabular}

Table 5. Paired Samples Test of TOA and TTM

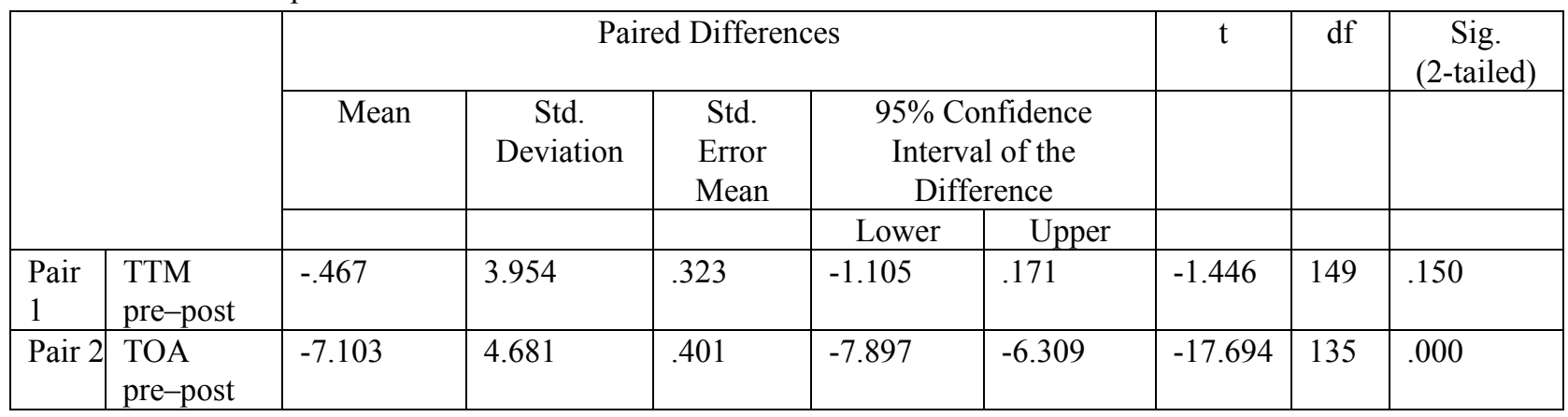


Table 6. Summary of the Questionnaire in View of TOA

\begin{tabular}{|l|l|l|l|l|l|}
\hline Factors of evaluation (F) & \multirow{2}{*}{ Items } & \multicolumn{4}{|l|}{ Degrees of evaluation } \\
\cline { 3 - 6 } & & $\begin{array}{l}\text { Strongly } \\
\text { Agree(4) }\end{array}$ & $\begin{array}{l}\text { Agree } \\
(3)\end{array}$ & $\begin{array}{l}\text { Disagree } \\
(2)\end{array}$ & $\begin{array}{l}\text { Strongly } \\
\text { Disagree (1) }\end{array}$ \\
\hline Theme (F1) & 5 & 32 & 90 & 12 & 2 \\
\hline Teacher (F2) & 5 & 37 & 73 & 22 & 4 \\
\hline Students (F3) & 5 & 17 & 87 & 29 & 3 \\
\hline Teaching material (F4) & 5 & 17 & 92 & 25 & 2 \\
\hline $\begin{array}{l}\text { Teaching \& learning } \\
\text { Environment (F5) }\end{array}$ & 5 & 20 & 84 & 28 & 4 \\
\hline Classroom activities (F6) & 5 & 25 & 91 & 17 & 3 \\
\hline
\end{tabular}

Table 7. Comparison on Evaluation Among all the Factors of TOA

\begin{tabular}{|c|c|c|c|c|c|c|c|}
\hline & F1 & F2 & F3 & F4 & F5 & F6 & F7 \\
\hline Result vector & 35.8111 & 33.0488 & 33.0212 & 28.5890 & 27.8465 & 34.1035 & 32.3434 \\
\hline
\end{tabular}

* F1 $=$ theme; $\mathrm{F} 2=$ teacher; $\mathrm{F} 3=$ students; $\mathrm{F} 4=$ teaching materials;

$\mathrm{F} 5=$ teaching \& learning environment; $\mathrm{F} 6=$ classroom activities;

F7= general teaching effects

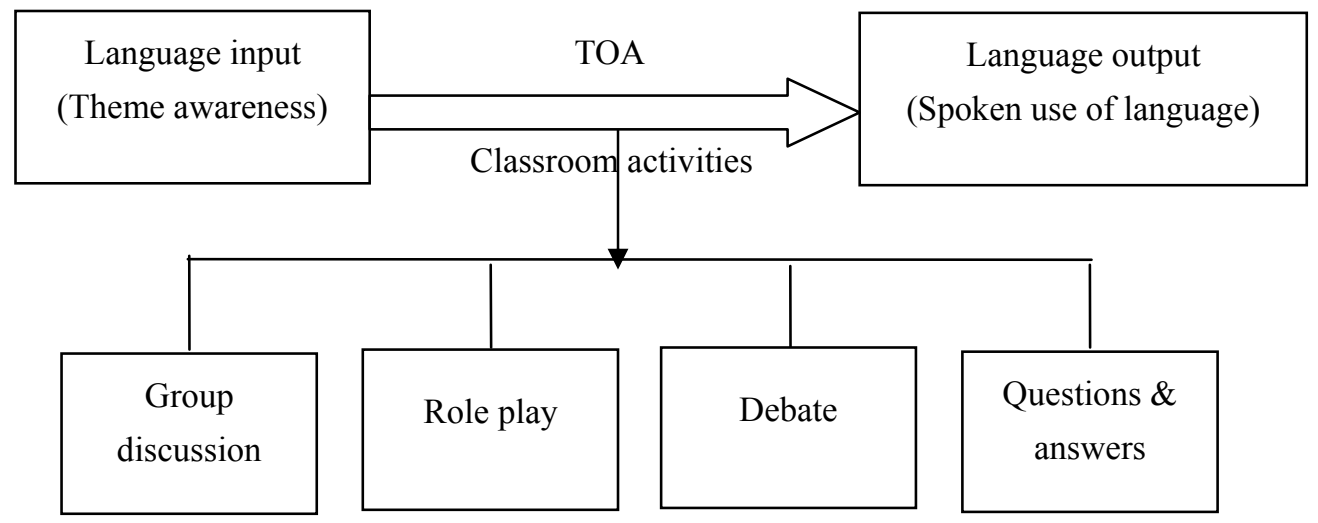

Figure 1. Dynamic classroom teaching

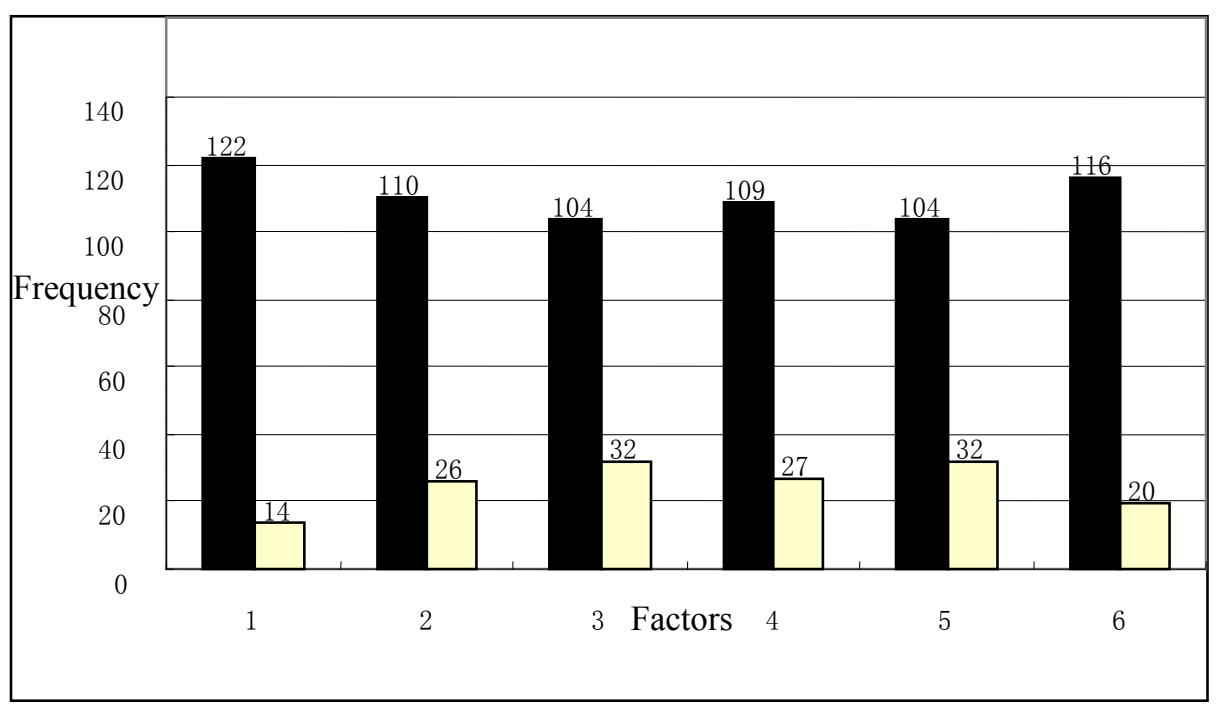

Figure 2. Comparison between agreement and disagreement towards the factors of TOA 